\title{
Articles
}

\section{The cost-effectiveness of different management strategies for Type I diabetes: a Swiss perspective}

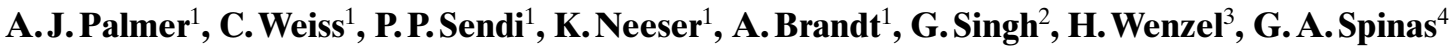 \\ ${ }^{1}$ IMIB, Institute for Medical Informatics and Biostatistics, Riehen, Switzerland \\ ${ }^{2}$ Stanford University, Palo Alto, California, USA \\ ${ }^{3}$ Roche Diagnostics, Mannheim, Germany \\ ${ }^{4}$ Division of Endocrinology and Diabetes, University Hospital Zurich, Switzerland
}

\section{Abstract}

Aims/hypothesis. A computer model was developed to determine the health outcomes and economic consequences of different combinations of diabetes interventions in newly diagnosed patients with Type I (insulin-dependent) diabetes in Switzerland.

Methods. We modelled seven complications of diabetes: hypoglycaemia, ketoacidosis, acute myocardial infarction, stroke, lower extremity amputation, nephropathy, and retinopathy. Transition probabilities and costs were taken from published literature. The Swiss health insurance payer perspective was taken. Various combinations of diabetes management strategies, including intensive or conventional insulin therapy and screening and treatment strategies for renal and eye disease were defined. Life expectancy, cumulative incidences of complications, and mean expected total lifetime costs per patient were calculated under six different management strategies. Incremental cost-effectiveness ratios were calculated in terms of costs per life-year gained compared with conventional insulin therapy alone.

Results. The addition of screening for microalbuminuria and retinopathy followed by appropriate treatment, if detected, were cost saving, with reduction in cumulative incidence of end stage renal disease and blindness respectively, and, in the case of microalbuminuria screening and treatment, an improvement in life expectancy. Intensive therapy improved life expectancy but increased total lifetime costs.

Conclusion/interpretation. Optimal management of Type I diabetic patients, including secondary and tertiary prevention, leads to reduced complications and improved life expectancy, with the increased costs of prevention offset to varying degrees by cost savings due to complications avoided. [Diabetologia (2000) 43: 13-26]

Keywords Switzerland, diabetes, cost-effectiveness, intensive therapy, screening, microalbuminuria, renal failure, blindness, disease modelling.
Received: 19 May 1999 and in final revised form: 4 August 1999

Corresponding author: Dr A.J. Palmer, IMIB, Institute for Medical Informatics and Biostatistics, 4125 Riehen, Switzerland

Abbreviations: ACE, angiotensin converting enzyme inhibitor; AMI, acute myocardial infarction; BR, background retinopathy; $\mathrm{C}$, conventional insulin therapy; CEA, cost-effectiveness analysis; CHF, Swiss francs; CVD, cardiovascular disease; DCCT, Diabetes Control and Complications Trial; ESRD, end-stage renal disease; I, intensive insulin therapy; LE, life expectancy; PR, proliferative retinopathy; PTCA, percutaneous transluminal coronary angioplasty; SBP, systolic blood pressure;Tc, total costs; T-CHOL, total cholesterol; UAE, urinary albumin excretion rate; MAU, microalbuminuria.
The importance of the economic aspects of Type I (insulin-dependent) diabetes management is increasing due to the rising health care costs, limited health care resources, increasing incidence and prevalence, and the potential to reduce incidence and progression of diabetes-related complications with optimal management [1-3]. Most clinical trials focus on short- to medium-term outcomes requiring the development of methods for forecasting long-term outcomes based on known short-term data. Additionally, improved diabetes management often involves relatively high amounts of short-term expenditure to avoid long-term complications, with the overall effect on total long-term costs being difficult to quantify empirically [4-6]. 
Disease modelling is one method to generate longterm health economic data in the absence of empirical data, based on the extrapolation of existing data [7]. Information generated by modelling studies can therefore help decision-makers to identify interventions with long-term effects that could be considered good "value for money" [8].

The Diabetes Control and Complications Trial (DCCT) compared conventional with intensive insulin therapy over a median follow-up period of 7.4 years [9]. Conventional therapy was defined as one or two daily subcutaneous injections of insulin, daily self-monitoring of urine or blood glucose, and education on diet and exercise. Patients attended their diabetes clinic every 3 months for a consultation with medical staff, a dietitian, and behavioural scientist. Intensive insulin therapy was defined as subcutaneous injected insulin three or more times daily, or continuous subcutaneous infusion with an insulin pump. The insulin dosage was adjusted according to the following factors: a) the results of self-monitoring of blood glucose done at least four times daily; b) daily dietary intake; and c) anticipated exercise. After an intensive education period (including 4 days of hospitalization and weekly telephone calls and clinic visits) during the first 2 months, patients attended the diabetes clinic every month. The goal of intensive insulin therapy was to maintain blood glucose concentrations as close as possible to the normal range [10]. Patients were screened for renal disease during the DCCT to monitor progression of microvascular disease rather than to facilitate appropriate therapy for nephropathy. Due to the prevailing clinical practice standards at the time of the DCCT patients were not routinely treated with angiotensin converting enzyme inhibitors (ACE) for microalbuminuria (MAU) or proteinuria, so the effect of addition of ACE to intensive therapy is not known. The DCCT did not assess progression from proteinuria to end-stage renal failure patients. Similarly, patients were monitored for the development and progression of diabetes-related microvascular ocular disease. The progression from proliferative retinopathy to blindness with or without retinal photocoagulation was not assessed.

Therefore, no long-term trials have been done that compare different management strategies from onset of diabetes through the development of microvascular disease and progression to end-stage disease over patients' lifetime. For this reason a disease model was developed to estimate medical and cost outcomes for the development of diabetes and related complications in Switzerland under different intervention strategies over the lifetime of patients. The model allows comparison of different combinations of interventions for which long-term studies have not been carried out, based on a synthesis of existing data. Using this technique, optimal lifetime treatment pathways can be identified, ensuring that the most appropriate treatment combinations are implemented. The hypothesis tested was: intensive insulin therapy and screening for - and treatment of MAU or retinopathy or both in Type I diabetic patients will improve clinical outcomes in comparison with conventional insulin therapy alone, while being efficient in health economic terms.

\section{Methods}

An incremental cost-effectiveness analysis was carried out. The intervention strategy used as the basis for comparison was conventional insulin therapy alone $(\mathrm{C})$, with no laser therapy for proliferative retinopathy, nor ACE inhibitor therapy for MAU or proteinuria. We compared seven intervention strategies with conventional therapy alone: conventional insulin therapy plus annual screening for proliferative retinopathy with 7-field fundus photography, and treatment with laser photocoagulation if proliferative retinopathy was detected $(\mathrm{C}+$ EYE); conventional insulin therapy plus annual screening for MAU with urine test strips, and treatment with Captopril $25 \mathrm{mg}$ three times daily if MAU was detected (3 positive results) $(\mathrm{C}+\mathrm{ACE})$; conventional therapy plus both eye and MAU screening $(\mathrm{C}+\mathrm{EYE}+\mathrm{ACE})$; intensive insulin therapy alone (I); insulin therapy plus annual screening for proliferative retinopathy with 7-field fundus photography, and treatment with laser photocoagulation if proliferative retinopathy was detected (I + EYE); intensive insulin therapy plus annual screening for MAU with urine test strips, and treatment with Captopril $25 \mathrm{mg}$ three times daily if MAU was detected (I + ACE); and intensive insulin therapy plus both eye and MAU screening $(\mathrm{I}+\mathrm{EYE}+\mathrm{ACE})$.

The disease process was modelled by seven Markov submodels, representing the development and consequences of renal disease, retinopathy, amputation, myocardial infarction, stroke, major hypoglycaemic events, and ketoacidosis. The course of the development of diabetes complications under a given clinical treatment strategy can be interpreted as a time series of clinical events and medical outcomes (e.g. incidence of complications, mortality). Different interventions or treatment strategies were reflected by the change of the key clinical variables and medical consequences, i. e. by a change of the incidence and severity of clinical events or progress of the disease. Key factors used in the calculation of transition probabilities are summarized (Table 1 ). The resulting incidence history of events was combined with a table of cost items related to interventions and events or complications due to the disease (Table 2). For each of these events, a series of related cost elements was built up. Total lifetime costs were calculated by summing over time and events. The clinical and cost outcomes for a typical cohort of newly diagnosed 19-year-old (the median age of onset of Type I diabetes in urban Swiss males [1]) diabetic patients, with no baseline complications, baseline $\mathrm{HbA}_{1 \mathrm{c}}$ of $8.5 \%$, total cholesterol (T-CHOL) of $200 \mathrm{mg} / \mathrm{dl}(5.2 \mathrm{mmol} / \mathrm{l})$, high density lipoprotein cholesterol (HDL) $50 \mathrm{mg} / \mathrm{dl}(1.3 \mathrm{mmol} / \mathrm{l})$, and a systolic blood pressure (SBP) of $110 \mathrm{mmHg}$ were compared under the different management strategies described previously. Changes in SBP, T-CHOL and HDL from baseline levels followed population-based changes with age [11, 12]. Based on these parameters, probabilities for clinical events were retrieved from published literature. Costs for each of the alternative intervention strategies assessed were calculated from reported resource consumption [5], and were adapted to the Swiss-specific situation by attaching relevant costs for 
Table 1. Summary of important factors used in the calculation of probabilities used in the model

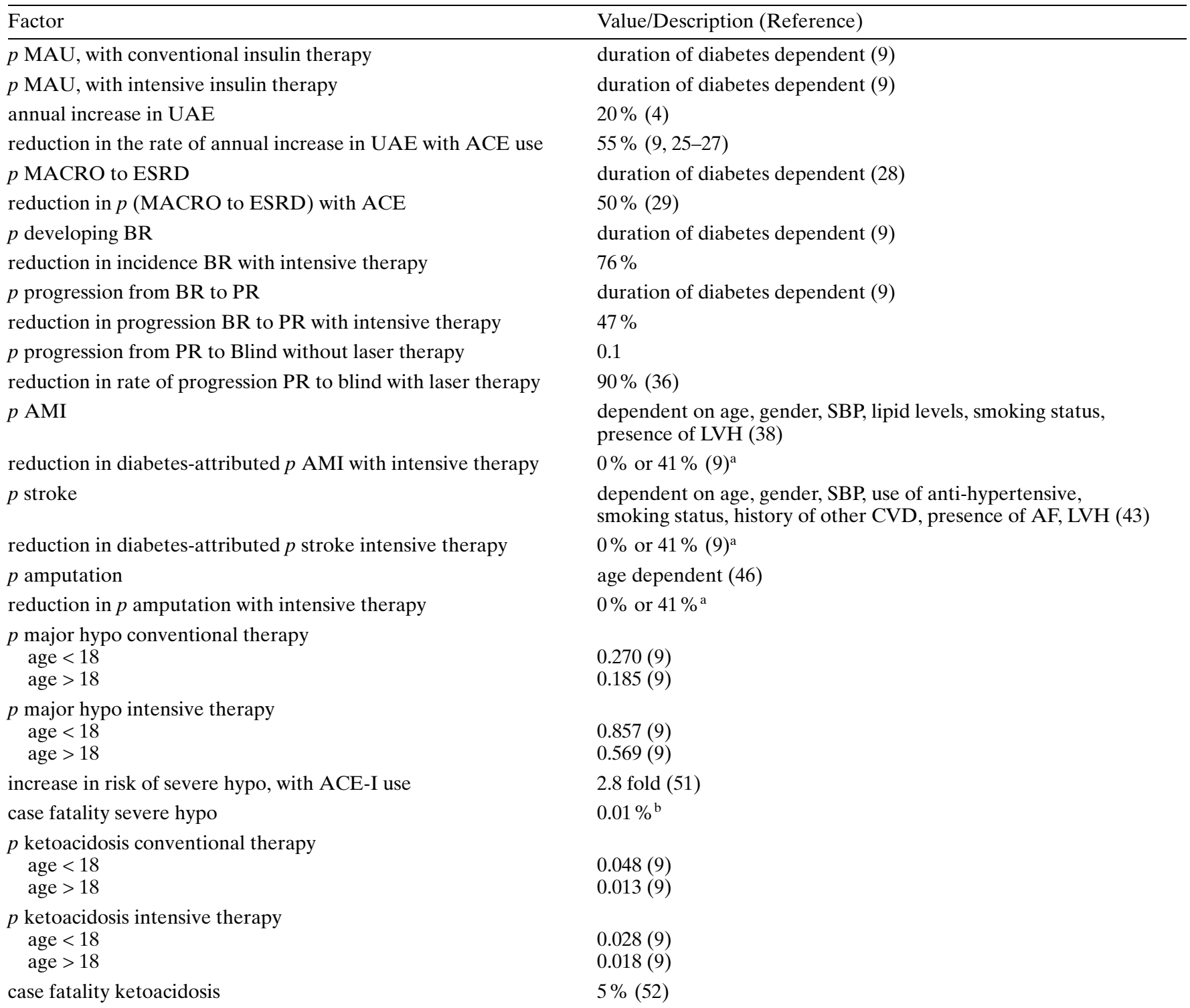

p, annual probability; hypo, hypoglycaemic event; ${ }^{a}$ two different values were tested for the effect of intensive therapy on macrovascular disease; ${ }^{\mathrm{b}}$ assumption

equipment, investigations, procedures, medications, and hospitalisation [13-17]. Costs for complications were taken directly from published Swiss sources $[14,16,18,19]$ or, where no Swiss specific data were available, were calculated from published resource consumption reported from the United States, combined with Swiss-specific costs for the resources used. The perspective of the Swiss third party payer was taken. All costs were calculated in Swiss francs (CHF) expressed in 1996 values. Only direct medical costs were considered.

Outcomes calculated were survival functions, life expectancy, cumulative incidence of complications, and mean expected total lifetime costs of diabetes management and complication treatment per patient. Incremental cost-effectiveness ratios for each intervention strategy were calculated in comparison with conventional insulin therapy alone, using the formula: $\left(\mathrm{TC}_{\mathrm{s}}-\mathrm{TC}_{\mathrm{c}}\right) /\left(\mathrm{LE}_{\mathrm{s}}-\mathrm{LE}_{\mathrm{c}}\right)$, where $\mathrm{TC}=$ the mean expected total lifetime direct costs, $\mathrm{LE}=$ life expectancy from baseline age expressed in years, $\mathrm{s}=$ the strategy being compared with con- ventional insulin therapy alone, and $\mathrm{c}=$ conventional insulin therapy alone.

Both undiscounted and discounted costs and clinical outcomes (life-years gained compared with conventional therapy only) were calculated. Due to controversy over which discount rates to use $[7,8,20,21]$, analyses were done with discounted rates of 3,5 and $6 \%$ for both cost and clinical outcomes.

Intensive insulin therapy resulted in a reduction of all macrovascular events combined by $41 \%(p=0.06)$ [9]. The DCCT, however, was not primarily designed to assess macrovascular outcomes, and with a relativety young patient population and short follow-up time, it was unlikely to show important differences in incidence of macrovascular disease. It has been shown that intensive insulin therapy reduces the development of early atherosclerosis [22]. Therefore, sensitivity analysis was done on the effect of intensive therapy on the incidence of stroke and AMI. We carried out one set of analyses assuming that it would reduce the diabetes-attributed risk of stroke and AMI 
Table 2. Cost items used in the model

\begin{tabular}{lll}
\hline Event & \multicolumn{2}{l}{ Costs (CHF) 1996 values } \\
\cline { 2 - 3 } & $\begin{array}{l}\text { event }+ \text { first } \\
12 \text { months costs } \\
\text { following event }\end{array}$ & $\begin{array}{l}\text { annual follow-up } \\
\text { after first } \\
\text { months }\end{array}$ \\
\hline conventional insulin therapy & $2496(5,13-17)$ & $2496(5,13-17)$ \\
intensive insulin therapy & $7729(5,13-17)$ & $4936(5,13-17)$ \\
annual screening for MAU & $29(15)$ & - \\
annual treatment costs & & - \\
with ACE & $888(13)$ & \\
annual screening for & & - \\
retinopathy & $208(15)$ & - \\
retinal photocoagulation & $743(77)$ & $1700(16,17,19)$ \\
AMI & $23024(16,17,19)$ \\
stroke & $33578(16,17,19)$ & $8687(16,17,19)$ \\
amputation & $35271(16,17,19)$ & $594(16,17,19)$ \\
haemodialysis & $63935(14)$ & $63935(14)$ \\
peritoneal dialysis & $48231(14)$ & $48231(14)$ \\
kidney transplant & $209500(14)$ & $147500(14)$ \\
blindness & $1000^{\mathrm{a}}$ & $1000^{\mathrm{a}}$ \\
ketoacidosis & $4230(16,78)$ & - \\
major hypoglycaemic event & $620(5,16)$ & - \\
\hline CHF, Swiss francs, 1996 & &
\end{tabular}

CHF, Swiss francs, 1996 values; ${ }^{\text {a }}=$ assumption; numbers in brackets represent references

by $41 \%$ and another that assumed there would be no impact of intensive therapy on incidence of stroke or AMI. Additional sensitivity analyses were done. One-way sensitivity analysis on life expectancy and total costs for patients treated with $\mathrm{I}+\mathrm{EYE}+\mathrm{ACE}$ was done to identify factors exerting a major influence on these outcomes. Each cost and probability variable was varied one at a time by $+/-10 \%$ while holding all other variables constant, and the effect on outcomes was observed. Threshold (break-even) analysis was done on the annual costs of intensive insulin therapy. This is a specialized

Fig. 1. Nephropathy sub-model (A), retinopathy sub-model (B)

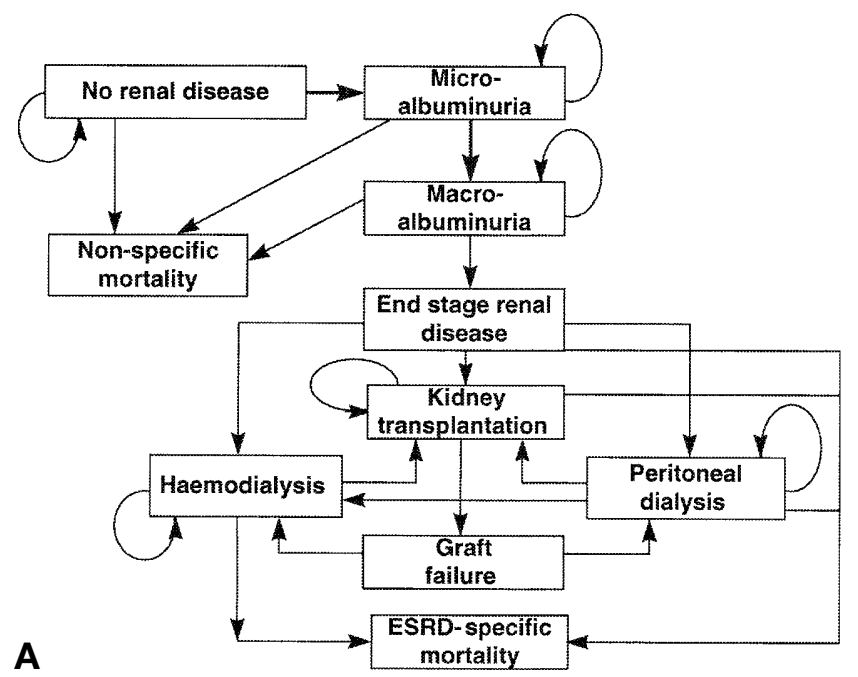

form of one-way sensitivity analysis in which the annual costs of intensive insulin therapy were varied until the total lifetime costs (costs of therapy + costs of treating events) were equal to the total costs for conventional therapy.

\section{The sub-model structures}

The full model structure was built up from a series of sub-models that simulate the progression of the seven important complications of diabetes considered. The sub-models were run in parallel, allowing the cohort to develop more than one complication simultaneously, reflecting real-life. Each sub-model was a Markov model using time- and state-dependent probabilities. The calculation cycle was 1 year. Overall mortality for the complete model was calculated by integrating complication-specific mortality calculated within each sub-model with non-complication-specific mortality [23]. The model was programmed using TOM (Tools for Outcomes Modeling) software from IMIB (Basel/Riehen, Switzerland).

Nephropathy sub-model. Diabetic nephropathy begins without clinical symptoms and, without intervention, can progress to end stage renal failure. The nephropathy sub-model simulated the progression from no renal complications to end stage renal disease (ESRD) (Fig. 1A). The cohort started in the state of "no microalbuminuria" (no MAU) [defined as a urinary albumin excretion rate (UAE) $<40 \mathrm{mg} / 24 \mathrm{~h}$ ], to the state of "MAU" (defined as UAE rate of $40-300 \mathrm{mg} / 24 \mathrm{~h}$ ). The rate of progression from "no MAU" to "MAU" was dependent on the cohort's baseline $\mathrm{HbA}_{1 \mathrm{c}}$ value [24] and duration of diabetes [9]. The rate of progression from "no MAU" to "MAU" is decreased by intensive therapy [9]. From the state of "MAU", the patient may progress to the state of "macroalbuminuria" defined as a UAE rate of more than $300 \mathrm{mg} / 24 \mathrm{~h}$. The rate of progression from "MAU" to "macroalbuminuria" with conventional therapy is calculated using a mean $20 \%$ annual increase in UAE [4]. The annual increase in UAE is decreased independently by both intensive insulin therapy and the use of ACE-I (by $55 \%$ ), independent of antihypertensive effects [9, 25-27]. From the state of "macroalbuminuria", the cohort could progress to ESRD. The rate of progression from "macroalbuminuria" to ESRD is dependent on the duration of macroalbuminuria [28], and is decreased (by $50 \%$ ) by the use of ACE-I [29]. The DCCT did not investigate the effect of intensive therapy on progression from macroalbuminuria to

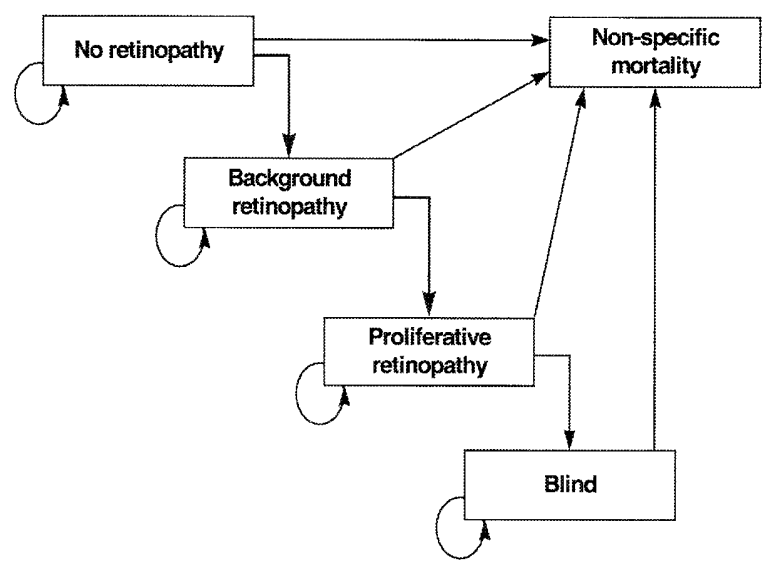




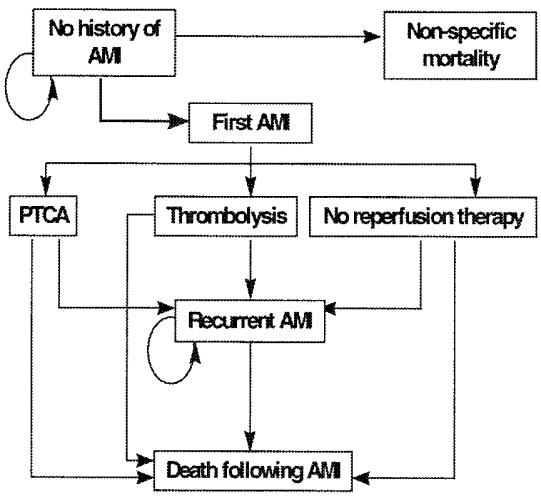

A

Fig. 2. AMI sub-model (A), stroke sub-model (B), amputation sub-model (C)

ESRD, and so it was conservatively assumed that it has no effect. When ESRD is reached, the cohort requires renal replacement therapy. Patients receive either haemodialysis $(80 \%)$, peritoneal dialysis $(15 \%)$, or kidney transplant $(6 \%)$ [18]. Patients with ESRD have a probability of death that is dependent on the type of renal replacement therapy they received $[30,31]$. Of those patients who received a kidney transplant, there is a time-dependent probability of graft failure, in which case the patient is transferred to either peritoneal or haemodialysis [31].

Retinopathy sub-model. Diabetic retinopathy is the leading cause of blindness in patients 25 to 74 years of age [32], and accounts for $12 \%$ of all new cases of blindness in the USA [33]. The basic pattern of progression is from no retinopathy, to background retinopathy, to proliferative retinopathy, and finally to blindness (Fig. 1B). The rate of progression from "no retinopathy" to the background retinopathy is dependent on the duration of diabetes and the $\mathrm{HbA}_{1 \mathrm{c}}$ value and is reduced (by $76 \%$ ) with intensive insulin therapy $[9,34]$. From background retinopathy, the patient can progress to proliferative retinopathy. The rate of progression to proliferative retinopathy is dependent on duration of diabetes, $\mathrm{HbA}_{1 \mathrm{c}}$ value, and is reduced (by $47 \%$ ) with intensive therapy $[9,34,35]$. The retinopathy sub-model differentiates between patients who are screened annually for retinopathy using 7-field fundus photography and those who are not screened. It is assumed that those patients who are screened will be treated with laser therapy, if proliferative retinopathy is detected. The rate of progression from proliferative retinopathy to blindness is reduced by $90 \%$ in patients treated with laser therapy [36].

AMI sub-model. Diabetic patients are at a two- to fourfold increased risk of AMI compared with the non-diabetic population [37]. The probability of having a first AMI depends on the patient's age, sex, smoking status, SBP, HDL, T-CHOL, and presence of left ventricular hypertrophy [38]. Approximately $6-10 \%$ of patients having a first AMI die immediately. The probability of immediate death depends on sex and age $[39,40]$. Those who survive the first hour are admitted to hospital, where the treatment options are either primary percutaneous transluminal coronary angioplasty (PTCA), thrombolysis, or no reperfusion therapy (i.e. intensive drug therapy). The probability of in-hospital death depends on the therapy re-

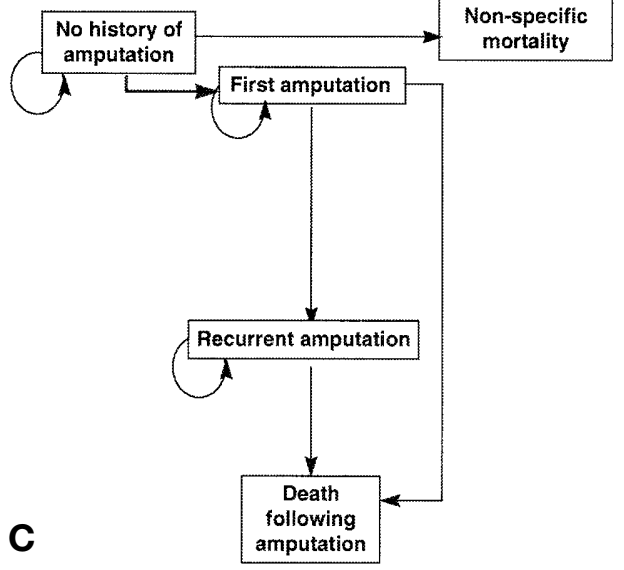

ceived, age, and sex [40-42]. Those patients who survive the inhospital period have a small probability of dying in the 12 months following discharge, dependent on age, sex, and type of reperfusion therapy received [40-42]. If the patient survives the first 12 months after discharge, he enters the corresponding states of "history of AMI, PTCA treated", "history of AMI, thrombolysis treated", or "history of AMI, no reperfusion". Each of these states carries different probabilities of death in the years following AMI, dependent on age, sex, and time since the first infarction (Fig. 2A) [40-42].

Stroke sub-model. Diabetic patients are at double the risk of stroke compared with patients without diabetes [37]. The probability of a first stroke is dependent on age, SBP, use of anti-hypertensive therapy, smoking status, a history of other cardiovascular disease (includes history of myocardial infarction, angina pectoris, coronary insufficiency, cardiac failure, and intermittent claudication), presence of atrial fibrillation, and presence of left ventricular hypertrophy [43]. Approximately $5 \%$ of diabetic patients having a first stroke die immediately [44].

Approximately $16 \%$ of diabetes patients admitted to hospital die in-hospital. The probability of in-hospital death depends on the patient's sex [44]. Those patients surviving the in-hospital period have a sex-dependent probability of death in the first year following the first stroke [44]. The subjects surviving the first year after the first stroke progress to the state of "history of stroke". Now the patient has an annual sex- and time-dependent probability of dying [44]. The surviving patients have an annual sex- and time-dependent probability of recurrent stroke (Fig. 2B) [45].

Amputation sub-model. Patients with diabetes have a 14 times higher risk of non-traumatic lower extremity amputation compared with the population without diabetes [46]. Peripheral neuropathy increases the risk of lower extremity amputation primarily through an increased tendency of the diabetic patient to have unrecognized cutaneous damage through trauma and pressure. Peripheral neuropathy increases the risk of lower extremity trauma through inhibited proprioception of the lower limb joints. Macrovascular disease impairs peripheral arterial circulation, with poor healing of damaged skin, chronic ulceration and infection. The combination of these factors independently contributes to an increased risk of non-traumatic amputation in diabetic patients [47]. The probability of amputation is subjet to age, sex, smoking status and blood pressure [46, 48, 49]. Due to the significant reduction of the incidence of peripheral neuropathy (by $60 \%$ ) with intensive therapy, as well as a trend towards reduction of the incidence of macrovascular events (by $41 \%$ ), the probability of amputation was assumed to be decreased by $41 \%$ with intensive therapy. Following ini- 


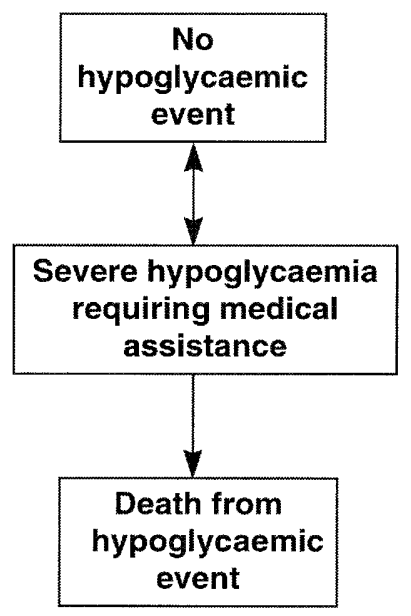

A

Fig. 3. Hypoglycaemia sub-model (A), ketoacidosis sub-model (B)

tial amputation, the annual incidence of re-amputation is four times higher than that of first amputation [46, 49]. Patients have an increased risk of death once amputation has occurred. This includes intra-operative death, which may range between $1 \%$ and $10 \%$ depending on the site of amputation (Fig. 2C).

Hypoglycaemia sub-model. Diabetic patients often experience episodes of hypoglycaemia, most of which require no external assistance and are treated by ingestion of oral glucose. In some cases, hypoglycaemia requires external medical assistance and could lead to loss of consciousness, coma or death. In the DCCT, the risk of hypoglycaemia with intensive insulin therapy was increased approximately three times in comparison with conventional therapy [9]. Additionally, the risk of a major hypoglycaemic event is increased by 2.8 times in Type I diabetic patients treated with ACE inhibitors [51]. Although no patients died due to hypoglycaemic events, severe hypoglycaemia is generally regarded as life-threatening, and we assumed a case fatality probability of 0.0001 in our model (Fig. 3A).

Ketoacidosis sub-model. Patients could experience an episode of ketoacidosis. Patients having an episode of ketoacidosis have a case fatality rate of $5 \%$ [52], although only one patient was reported to have died from ketoacidosis in the DCCT (Fig. 3B), [9].

\section{Results}

The mean expected total lifetime costs per patient, the life expectancy from baseline age, and the incremental cost-effectiveness ratio (costs per life-year gained) are summarized (Table 3). Total lifetime costs and life expectancy under the two different assumptions regarding the effect of intensive insulin therapy on macrovascular disease discussed previously are shown. The effect of using different discount rates on mean expected total lifetime costs and lifeyears gained compared with conventional therapy alone are summarized (Table 4).
Table 3. Summary outcomes (non-discounted)

\begin{tabular}{|c|c|c|c|c|c|c|}
\hline & \multicolumn{2}{|c|}{ LE (years) } & \multicolumn{2}{|c|}{$\mathrm{TC}(\mathrm{CHF})$} & \multicolumn{2}{|l|}{ CLYG } \\
\hline & + & - & + & - & + & - \\
\hline $\mathrm{C}$ & 45.22 & 45.22 & 314643 & 314643 & basis & basis \\
\hline $\mathrm{C}+\mathrm{EYE}$ & 45.22 & 45.22 & 309 & 309 & $\mathrm{D}$ & $\mathrm{D}$ \\
\hline $\mathrm{C}+$ & 49.45 & 49.45 & 279593 & 279 & $\mathrm{D}$ & $\mathrm{D}$ \\
\hline $\mathrm{C}+\mathrm{EYE}+\mathrm{ACE}$ & 49.45 & 49.45 & 272249 & 272249 & $\mathrm{D}$ & $\mathrm{D}$ \\
\hline I & 52.65 & 51.55 & 407785 & 399097 & 12536 & 13342 \\
\hline $\mathrm{I}+$ & 52.65 & 51.55 & 413 & 404 & 13276 & 14218 \\
\hline $\mathrm{I}+\mathrm{ACE}$ & 55.12 & 53.80 & 416 & 408047 & 10277 & 10886 \\
\hline $\mathrm{I}+\mathrm{EYE}+\mathrm{ACE}$ & 55.12 & 53.80 & 421641 & 413377 & 10808 & 11507 \\
\hline
\end{tabular}

EYE, screening for proliferative retinopathy, followed by laser therapy if detected; ACE, screening for microalbuminuria, followed by angiotensin converting enzyme inhibitor therapy if detected; TC, mean expected total lifetime costs per patient, undiscounted; CLYG, costs per life year gained in comparison to conventional therapy alone; +, assumes reduction in attributed risk of myocardial infarction and stroke due to diabetes of $41 \%$ with intensive therapy; -, assumes no effect of intensive therapy on myocardial infarction and stroke incidence; $\mathrm{D}$, dominant strategy

Table 4. Effect of using different discount rates on the mean expected total lifetime direct costs per patient (Swiss francs, expressed in 1996 values), and life years gained compared with conventional insulin therapy only

\begin{tabular}{lcrr}
\hline \multicolumn{4}{c}{ Annual discount rate } \\
\cline { 2 - 4 } & $3 \%$ & $5 \%$ & $6 \%$ \\
\hline Effect on total lifetime costs & & \\
C & 133276 & 85769 & 71176 \\
$\mathrm{C}+$ EYE & 133240 & 86807 & 72472 \\
$\mathrm{C}+$ ACE & 118853 & 79391 & 67427 \\
$\mathrm{C}+\mathrm{EYE}+$ ACE & 118356 & 80235 & 68594 \\
$\mathrm{I}$ & 180380 & 124683 & 107690 \\
$\mathrm{I}+\mathrm{EYE}$ & 184457 & 128035 & 110755 \\
$\mathrm{I}+\mathrm{ACE}$ & 190539 & 134159 & 116617 \\
$\mathrm{I}+\mathrm{EYE}+\mathrm{ACE}$ & 194580 & 137500 & 119676
\end{tabular}

Effect on life years gained compared with conventional therapy only

$\begin{array}{llll}\text { C } & \text { basis } & \text { basis } & \text { basis } \\ \text { C + EYE } & 0 & 0 & 0 \\ \text { C + ACE } & 1.05 & 0.50 & 0.30 \\ \text { C + EYE + ACE } & 1.05 & 0.50 & 0.30 \\ \text { I } & 1.84 & 0.81 & 0.55 \\ \text { I + EYE } & 1.84 & 0.81 & 0.55 \\ \text { I + ACE } & 2.24 & 0.93 & 0.62 \\ \text { I + EYE + ACE } & 2.24 & 0.93 & 0.62\end{array}$

EYE, screening for proliferative retinopathy, followed by laser therapy if detected; ACE, screening for microalbuminuria, followed by angiotensin converting enzyme inhibitor therapy if detected; The addition of screening and treatment for retinopathy has no effect on life expectancy

The contribution of different interventions and complications to the mean expected lifetime costs per patient was analysed (Table 5). With conventional insulin therapy alone, the major cost driver was the cost of renal failure. These costs are substantially reduced with the addition of screening for MAU and appropriate ACE therapy. For intervention strate- 
Table 5. Mean total lifetime costs (non-discounted) under different management strategies, broken down by cost element

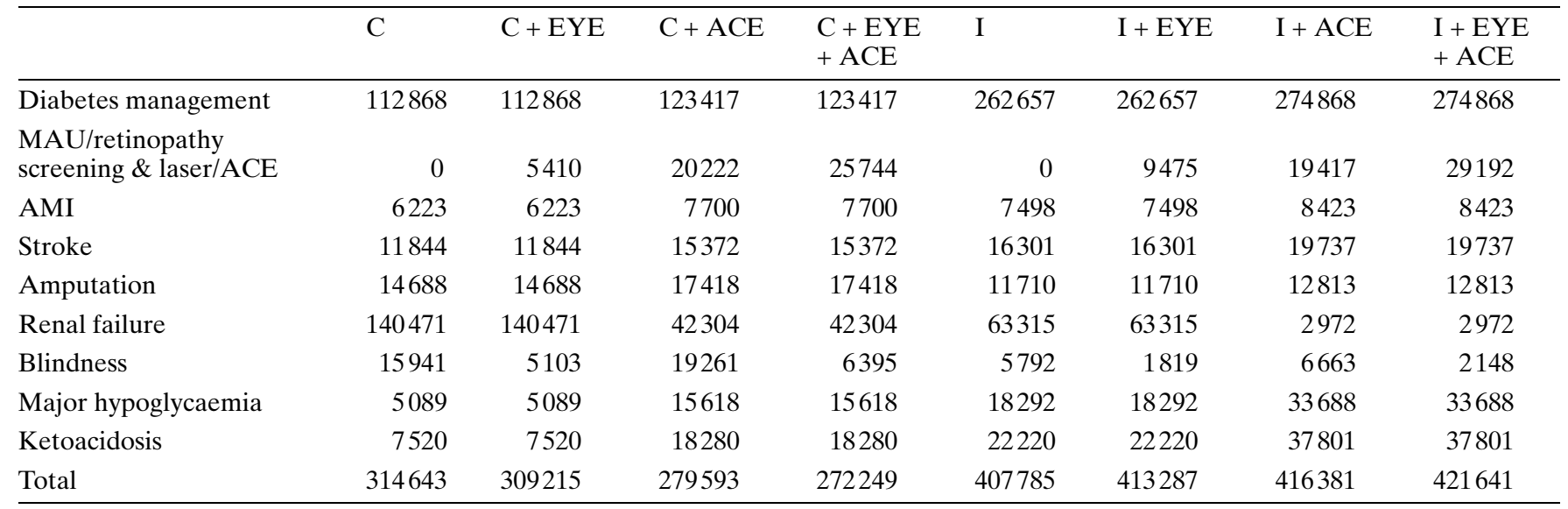

EYE, screening for proliferative retinopathy, followed by laser therapy if detected; ACE, screening for microalbuminuria, followed by angiotensin converting enzyme inhibitor therapy if detected; costs expressed in Swiss francs, 1996 values. Costs

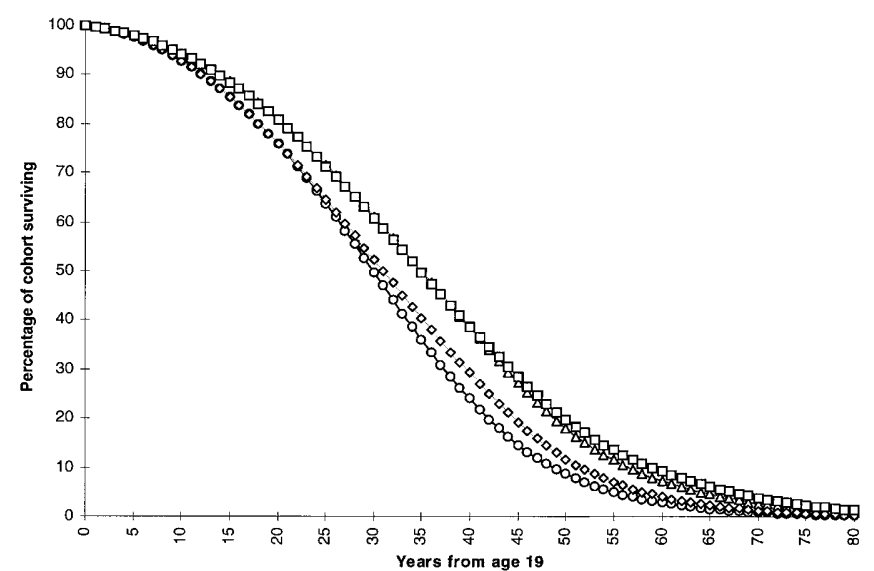

Fig.4. Survival function, showing the percentage of the cohort alive over the simulation period. Circles, C; diamonds, $\mathrm{C}+\mathrm{ACE}$; triangles, I; squares, I + ACE

gies, including intensive insulin therapy, the main cost driver is intensive therapy itself, although this is offset to some extent by the reduction in the costs due to renal disease, amputation, and blindness.

Survival functions, cumulative incidence of ESRD, blindness, and amputation over the simulation period were calculated. The survival curves are shifted to the right with ACE therapy due to the reduction in excess mortality from renal failure in the period of 25 years from baseline age. Intensive therapy has a greater shift to the right than ACE inhibitor therapy due to the additional effect of reduced amputation, AMI and stroke. The combination of intensive and ACE therapy shows the maximal effect on survival function. Intervention strategies including retinopathy screening and treatment are not shown as they have no effect on survival (Fig. 4). of diabetes management refer to the costs of intensive or conventional insulin therapy and include consultations, investigations, insulin, syringes, needles, lancets, blood glucose monitors, as defined in the DCCT
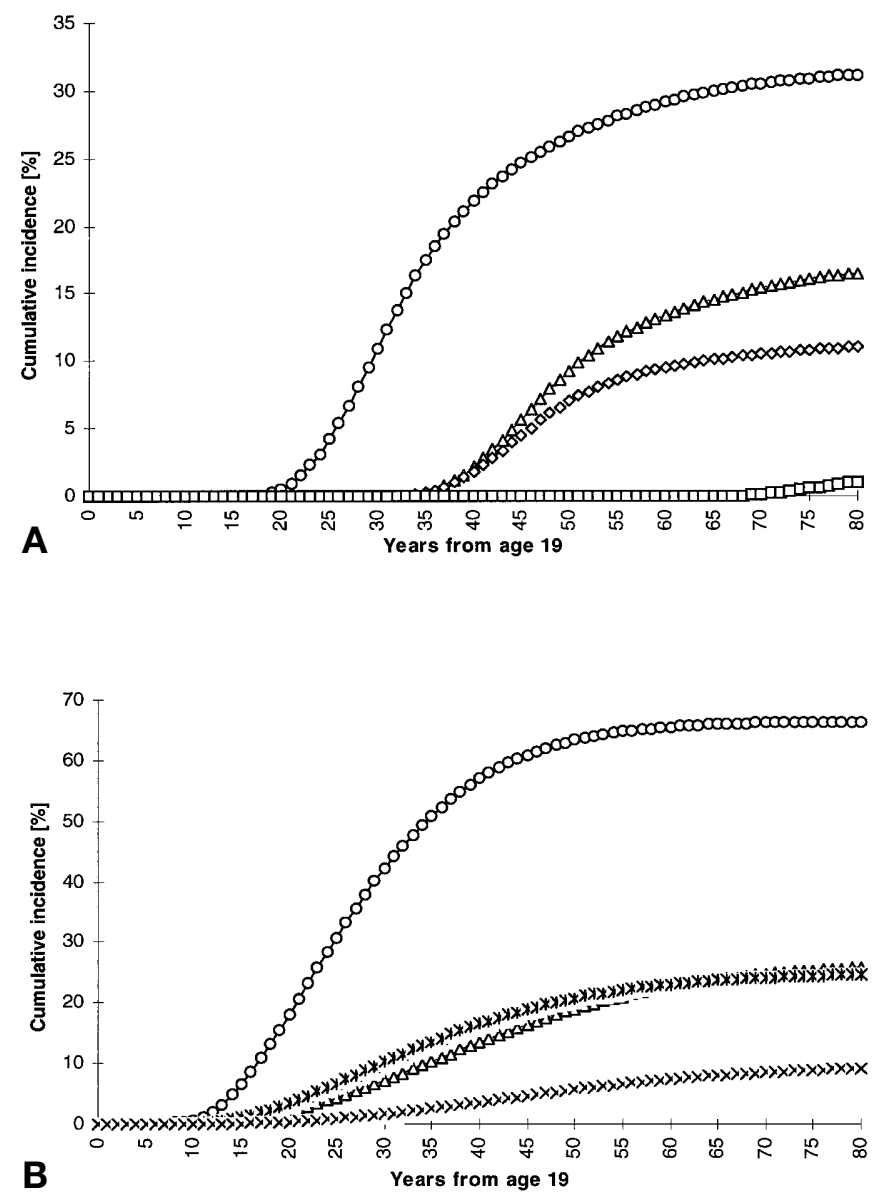

Fig. 5. Cumulative incidences of end stage renal disease (A), and blindness (B) within the cohort over the simulation period. Circles, C; diamonds, C + ACE; triangles, I; squares, I + ACE; $*, \mathrm{C}+\mathrm{EYE} ; \mathrm{x}, \mathrm{I}+\mathrm{EYE}$ 

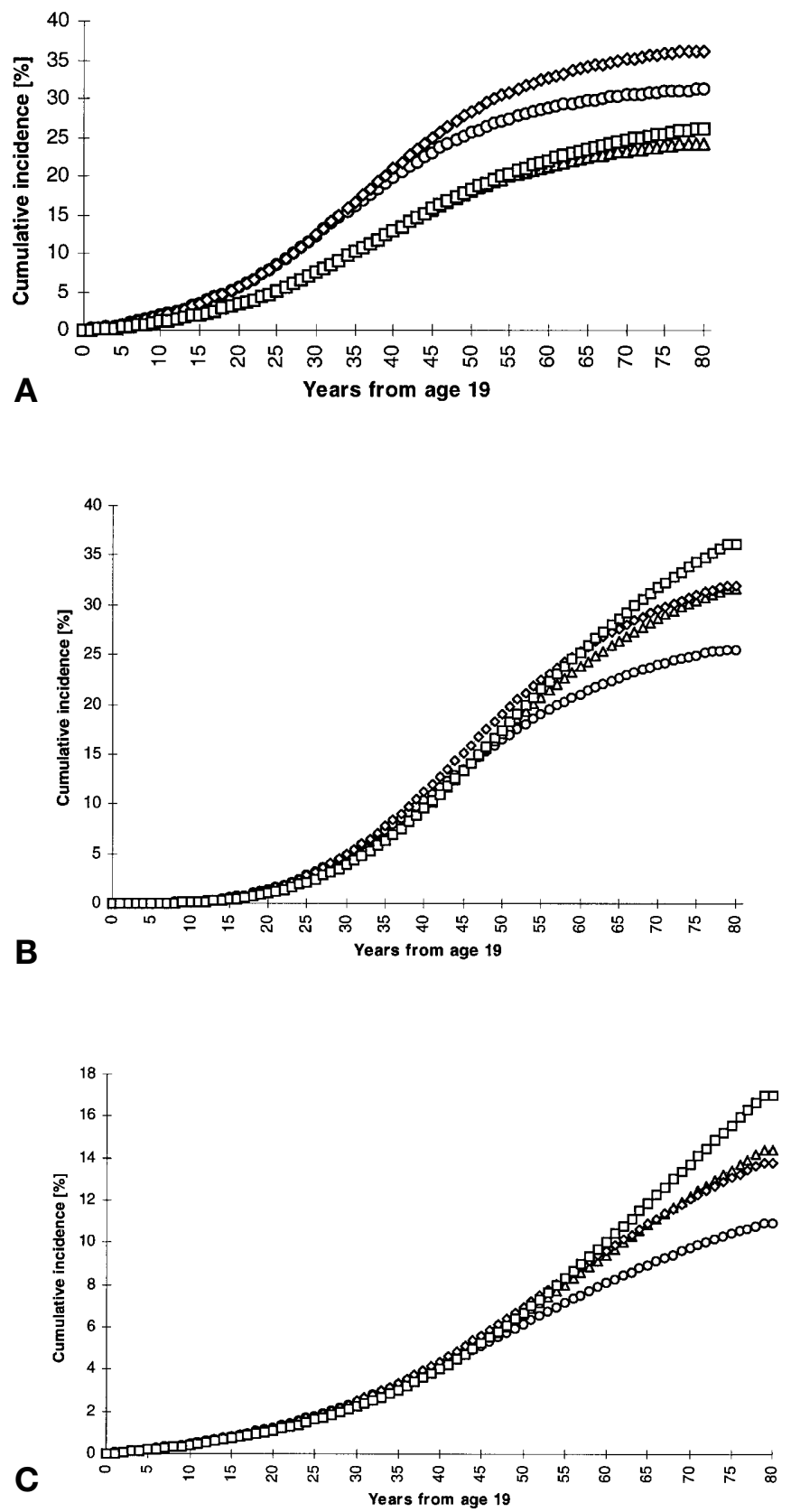

Fig. 6. Cumulative incidence of first amputation (A), first AMI (B), and first stroke (C) within the cohort over the simulation period. Circles, $\mathrm{C}$; diamonds, $\mathrm{C}+\mathrm{ACE}$; triangles, I; squares, I + ACE

Addition of ACE therapy to conventional therapy has a greater effect than intensive therapy on reducing cumulative incidence of ESRD. In this study, the effect of intensive therapy is possibly underestimated because of the assumption that it would have no effect on progression from proteinuria to renal failure. The combination of intensive insulin therapy and ACE could almost eliminate the development of ESRD (Fig. 5A).

Without any additional intervention, blindness will occur in approximately $42 \%$ of patients by the age of
50 years. Intensive therapy alone will reduce this to $7 \%$, addition of screening and laser therapy to conventional therapy will reduce this to less than $10 \%$, and the combination of intensive therapy plus screening and laser therapy will have the optimal effect by reducing cumulative incidence of blindness at age 50 years to less than $2 \%$ (Fig. $5 \mathrm{~B}$ ).

The cumulative incidence of first amputation is reduced from approximately $30 \%$ with conventional therapy to $22 \%$ with intensive insulin therapy alone. Paradoxically, the addition of ACE to intensive therapy increases the cumulative incidence of amputation. This effect on cumulative incidence is also seen in AMI and stroke with intensive therapy or ACE treatment or both. This is because the patients in the cohorts treated with intensive therapy or ACE or both have a greater life expectancy, exposing these surviving patients to the increasing risk of macrovascular events associated with increasing age (Figs. $6 \mathrm{~A}-6 \mathrm{C})$. By age 50 patients have experienced 5, 15, 17 , and 30 major hypoglycaemic events under conventional therapy alone, conventional plus ACE, intensive, and intensive plus ACE, respectively (Fig. 7).

One-way sensitivity analysis showed that the annual cost of intensive therapy had the greatest impact on the total lifetime costs in patients treated with a combination of intensive insulin therapy, eye, and MAU screening and treatment. Reduction in diabetes-attributed risk of AMI and reduction in incidence and progression of MAU with intensive insulin therapy had the greatest impacts on life expectancy (Figs. 8,9 ). Break-even analysis of the annual costs of intensive insulin therapy, either alone or in combination with eye and MAU screening strategies, were Swiss francs (CHF) 3130 and CHF 2960 per year respectively (Fig. 10).

\section{Discussion}

The addition of annual screening for MAU or retinopathy or both to conventional insulin therapy leads to cost savings and, in the case of MAU screening and ACE treatment, to an improvement of life expectancy. Therefore, these intervention strategies are regarded as "dominant" to conventional therapy alone in health economic terms. These results correspond to those of other cost-effectiveness studies of screening for MAU and retinopathy $[4,53]$. In terms of clinical outcomes (life expectancy and reduction of complications), the optimal management strategy most likely to lead to the attainment of Saint Vincent Declaration targets [54] is a combination of intensive insulin therapy, including regular, frequent self monitoring of blood glucose, 3-monthly $\mathrm{HbA}_{1 \mathrm{c}}$ monitoring, and regular screening for early complications and appropriate treatment if the complications are detected. This is achieved with only moderate in- 


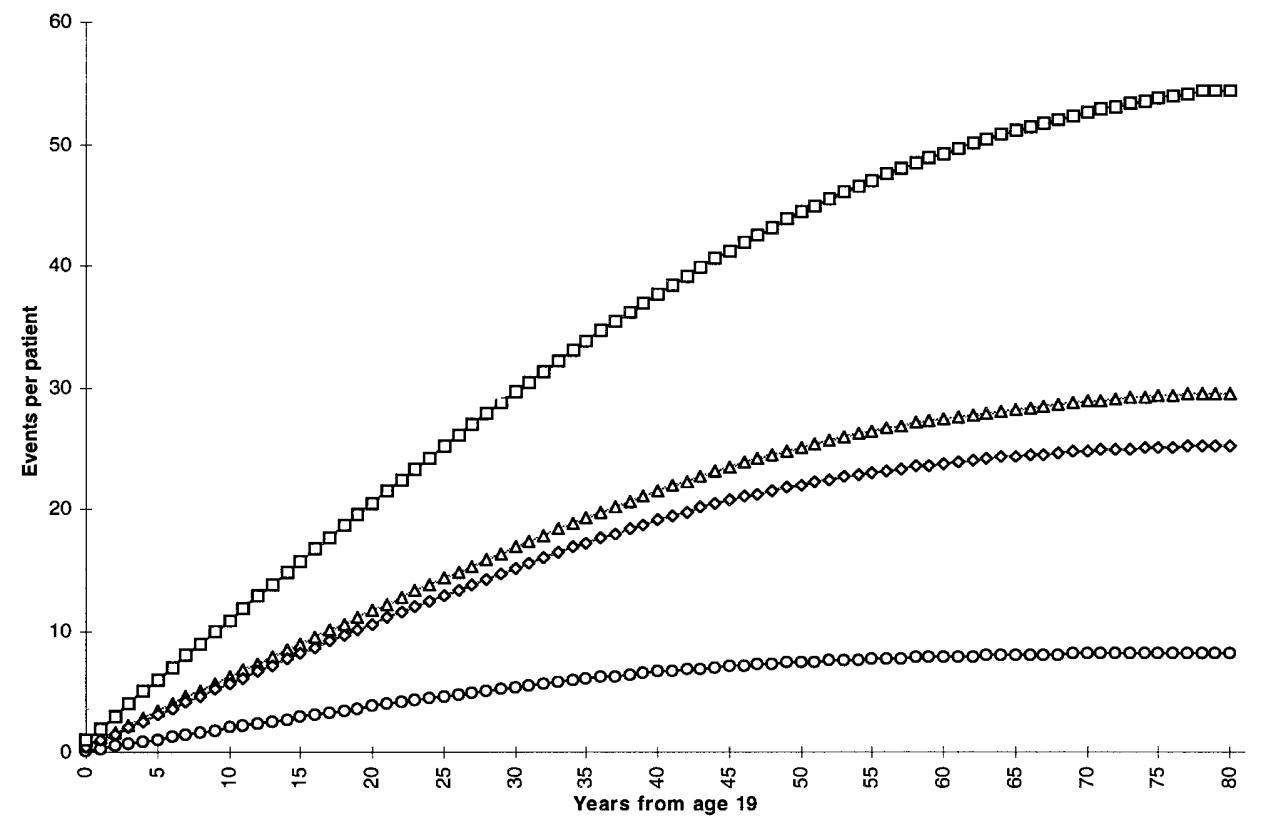

Fig. 7. Cumulative events per patient of major hypoglycaemia. Circles, C; diamonds, C + ACE; triangles, I; squares, I + ACE

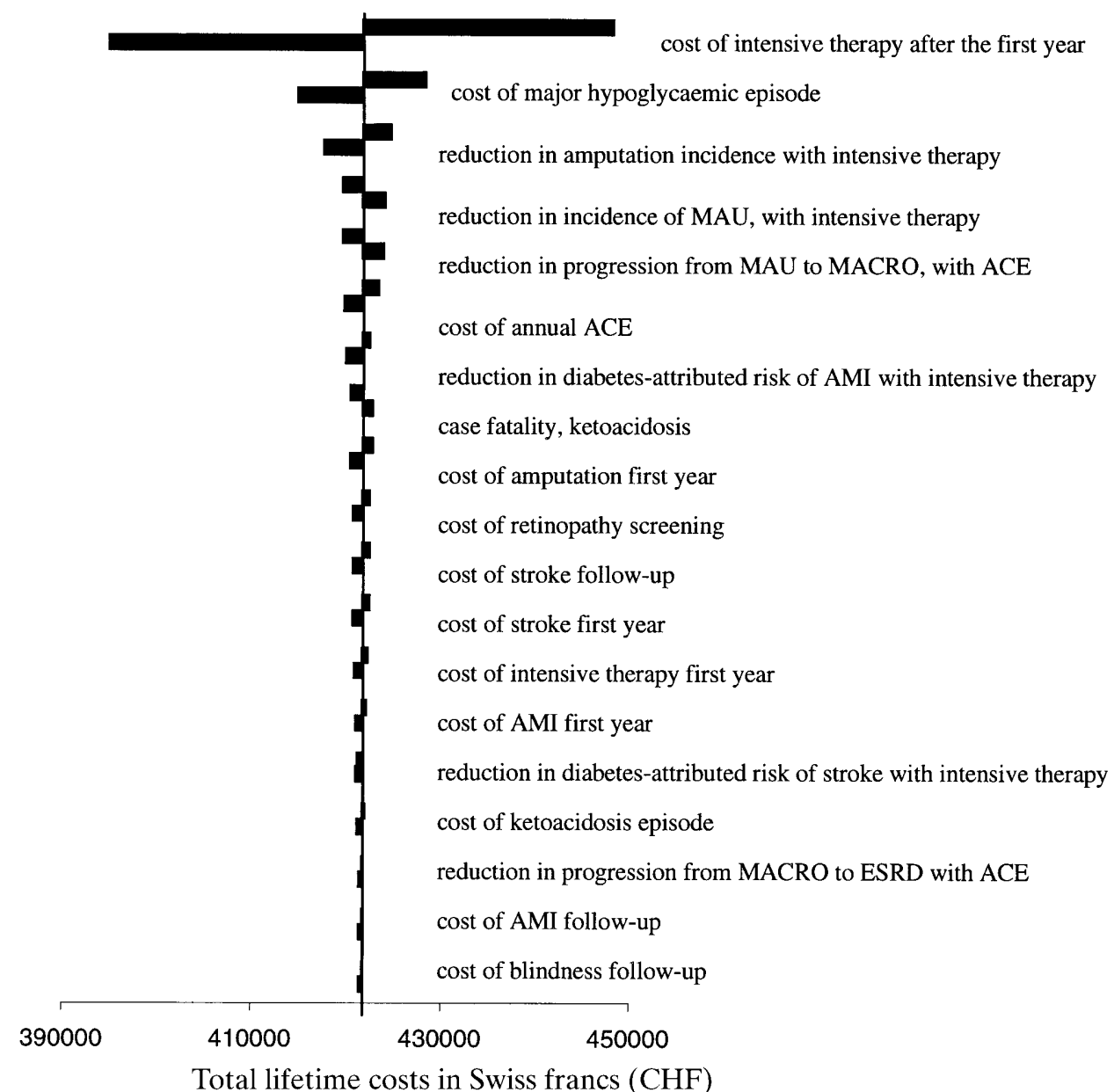

Fig. 8. One-way sensitivity analysis on total lifetime costs. The central vertical line represents the total lifetime costs for intensive therapy calculated using the baseline cost and probability estimations (Tables 1,2). Each parameter was varied one at a time by $+/-10 \%$. The relative size of the impact is represented by the relative width of the corresponding horizontal bar 


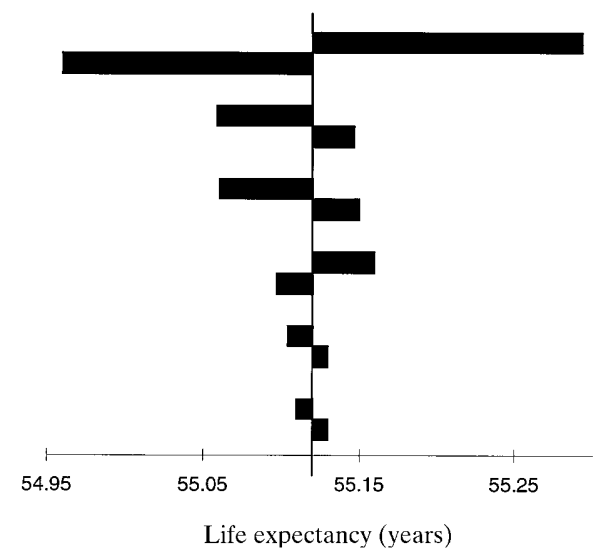

Fig.9. One-way sensitivity analysis on life expectancy. The central vertical line represents the life expectancy for intensive therapy calculated using the baseline probability estimations (Table 1). Each parameter was varied one at time by $+/-10 \%$. The relative size of the impact on life expectancy is represented by the relative width of the corresponding horizontal bar

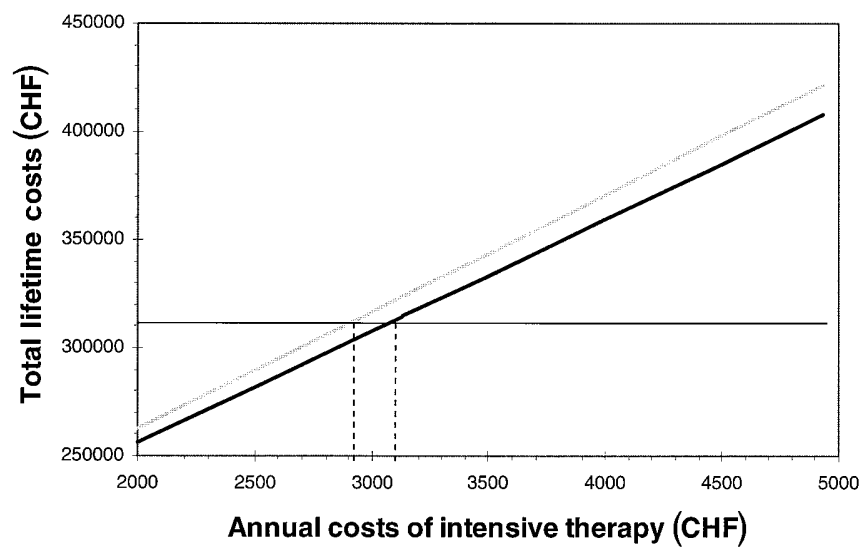

Fig. 10. Break-even analysis of the annual costs of intensive insulin therapy. Horizontal line = total lifetime costs per patient treated with conventional insulin therapy alone. Diagonal line $=$ lifetime costs for patients treated with intensive therapy alone (darker line) or I + EYE + ACE (lighter line) as the annual costs of intensive therapy is varied from CHF 2000 to CHF 5 000. Intersection points = break-even values for the annual costs of intensive insulin therapy. If the annual costs of intensive insulin therapy are less than CHF 2960 per year, the total lifetime costs per patients will be lower than those of patients treated with conventional therapy alone. $\mathrm{CHF}$, Swiss francs

creases in total direct costs, representing good costeffectiveness when rated on international scales (Table 3) $[55,56]$. These results correspond well to those generated in another long-term modelling study that showed an improvement in life expectancy of 5.1 years with intensive therapy combined with ACE therapy and an incremental cost-effectiveness ratio of \$US 28661 per life-year gained (outcomes discounted at $3 \%$ per annum) [6]. Whereas the strategy $\mathrm{I}+\mathrm{EYE}+\mathrm{ACE}$ leads to the greatest improvement

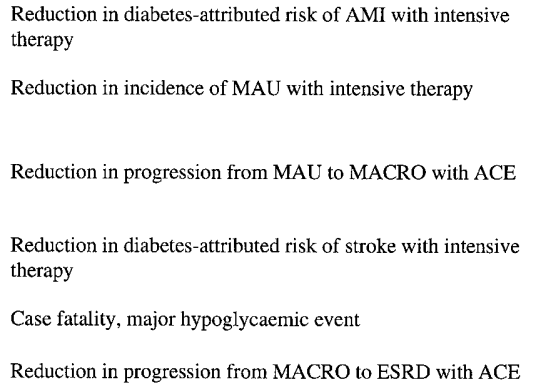

in life expectancy and reduction in long-term complications, the strategy $\mathrm{C}+\mathrm{EYE}+\mathrm{ACE}$, with both costs savings and improved life expectancy (although a lesser improvement in life expectancy than with $\mathrm{I}+\mathrm{EYE}+\mathrm{ACE}$ ) could be considered more efficient. The incremental cost-effectiveness ratio of $\mathrm{I}+$ $\mathrm{EYE}+\mathrm{ACE}$ vs C + EYE + ACE is CHF 133174 if both costs and life-years gained are discounted at $3 \%$ (range: CHF 9009 if costs discounted at $6 \%$, life-years gained not discounted, to CHF 441128 if costs not discounted and life-years gained discounted at $6 \%$ ). The current analysis does not assess the effect of interventions on quality-adjusted life expectancy (see below) and thus possibly underestimates the effect of intensive insulin therapy on quality of life due to complications such as neuropathy/amputation, and possibly stroke and AMI, being avoided. While C + EYE + ACE appears more attractive from a purely economic point of view, a primary goal of a health care system is to prevent the preventable. The ethical question of first waiting until patients develop microvascular complications, then treating them, needs to be addressed elsewhere.

A recent survey of Swiss patients with diabetes [57], showed that among Type I patients only $67 \%$ regularly monitor their blood glucose concentrations (frequency per day not specified), $68 \%$ had a $\mathrm{HbA}_{1 \mathrm{c}}$ measurement within the last 6 months, $3 \%$ had a measurement of UAE within the last 6 months, and $84 \%$ had a funduscopic examination in the last 12 months. Clearly there is room for improvement in the management of Type I diabetic patients in Switzerland. The fact that only $3 \%$ of Type I patients had their UAE monitored in the previous 6 months is of particular concern, considering the potential to avoid morbidity and mortality associated with renal disease with early recognition and appropriate intervention

The direct costs of blindness due to diabetic retinopathy are not known in Switzerland. An estimate of CHF 1000 was used as the annual direct costs of blindness per patient. This estimate is conservative because the costs per patient for training, special appliances and aids are approximately CHF 24000 to 
54000 (personal communication, Association of the Blind and Visually Impaired, Bern, Switzerland), although not all of these costs would be borne by the health insurance company. Thus, it is possible that the cost savings for blindness avoided by screening for and treatment of proliferative retinopathy and intensive therapy are underestimated in this analysis.

The life expectancies projected by the model under conventional therapy alone correspond closely to those reported recently for a German population in which diabetic patients with an age of onset of less than 30 years had life expectancies of 52.3 years [58].

The major clinical disadvantage of intensive insulin therapy and ACE therapy is the increased incidence of major hypoglycaemia. The risk of major hypoglycaemia is increased 3 times with intensive therapy and 2.8 times with ACE treatment. The model assumes that the increase in risk due to these two interventions is independent and multiplicative, although the interactions in real life are not known and need to be confirmed by empirical observation. The increase in total costs due to major hypoglycaemic events is relatively small compared with the cost savings gained by the reduction of other complications (Table 5).

Intensive insulin therapy was conservatively assumed to have no effect on the progression from proteinuria to ESRD. In reality, it is possible that intensive therapy reduces progression of proteinuria, in which case the effects of intensive therapy on reducing ESRD have been underestimated by the model.

Screening for proliferative retinopathy was assumed to be by 7-field fundus photography on an annual basis. Other screening methods, like dilated ophthalmoscopy or other time intervals for screening that may also be cost-effective were not compared in this analysis $[53,59]$.

There was controversy as to which discount rate to apply [7, 8] thus the effect of three different discount rates was analysed (Table 4). Discounting takes into account the time preference for money and health improvements. Secondary screening and treatment, and particularly intensive insulin therapy, require a relatively high level investment in the short-term. The pay-off from these additional interventions is not seen until after 10-15 years when a reduction in costly complications, particularly renal disease, is seen relative to conventional insulin therapy. The decrease in lifeyears gained compared with conventional therapy seen with increasing discount rates reflects the predominantly long-term clinical benefits seen with the interventions analysed. Intervention strategies including intensive insulin therapy become less attractive from the health-economic viewpoint as higher discount rates for clinical and economic outcomes are applied.

Inclusion of indirect costs in health economic analyses is controversial [60]. Indirect costs are often not included in health-economic analyses, despite coun- try-specific recommendations [8,61]. Reasons for exclusion of indirect costs include the perspective of the payer taken, controversy over the methodology used to calculate indirect costs [60] and difficulty in accurate accounting [62]. In our analysis, where the perspective of the health insurance payer was taken and where no data were available, indirect costs were not included in the analysis.

Lifetime costs were most sensitive to variation of the annual costs of intensive insulin therapy. Variations of the costs per major hypoglycaemic event also had an impact because of the higher frequency of hypoglycaemic events seen in the combination of intensive insulin and ACE therapy. Variations in the costs of "end-stage" complications, such as blindness, renal failure, AMI and stroke had relatively little impact on total cost outcomes because of the less frequent occurrence of these complications with a combination of intensive insulin therapy, MAU and eye screening and treatment.

The break-even point for the annual costs of intensive insulin therapy was approximately CHF 3000 compared with the current costs of CHF 4936 per year. If intensive insulin therapy could be implemented with an annual cost below this break-even point, overall cost savings would be seen.

The validity of all clinico-economic analyses is limited by the availability of appropriate medical and cost data. The data available from the literature are themselves limited by the aims, populations, and methodology of the clinical trials that generate the data. For the comparison of conventional and intensive insulin therapies, the model takes DCCT data from the USA and assumes that intensive therapy can be implemented in the Swiss population with similar effectiveness. The DCCT population was a select population that was highly motivated, with a high intelligence quotient and relatively well educated [63]. This possibly does not reflect the general Type I diabetic population either in the USA or in Switzerland. As it is unlikely, however, that a DCCT-like trial will ever be repeated, either in Switzerland or the USA, the available data must be used.

Possible effects of ACE inhibitors on reducing incidence and progression of other complications including retinopathy [64-66], neuropathy $[67,68]$, and improved survival after AMI [69-72] were not taken into account. Similarly, possible improvements in survival post-AMI seen with intensive therapy [73] were also not considered in the model. Other important interventions such as intensive blood pressure control [74], aspirin for primary and secondary cardiovascular disease prevention [75] smoking cessation programmes, and lipid modification, were not explicitly modelled.

Measures of dispersion of the results were not calculated for a number of reasons. Firstly, for an accurate estimation of confidence intervals each probabil- 
ity and cost item needs to be defined as a distribution. In reality, it is difficult to find probabilities and costs even as single (point value) numbers and distributions are rarely reported. Therefore, distributions must be artificially created or assumed, leading to the calculation of artificial confidence intervals that may or may not reflect reality. Secondly, in a complex model, even if distributions for probabilities and costs were available, the usual methods for calculation of variance, such as first and second order Monte Carlo simulation would take an estimated 3-4 weeks per simulation. Thus, the more than 30 separate simulations that were necessary for the current study would have taken as long as 2 years to run. The model was designed to give results within minutes rather than weeks to allow the speedy exploration of different data sets or assumptions in the real-time setting.

Finally, quality of life changes were not explicitly assessed in the analysis. Despite the rigors of intensive insulin therapy and the increased risk of hypoglycaemia, quality of life did not deteriorate in the intensively treated patients of the DCCT, although patients with three or more severe hypoglycaemic events were at an increased risk of measurable psychological distress [76]. Furthermore, it is implicit that interventions leading to a reduction in the incidence and progression of irreversible complications would lead to an improvement in quality of life.

Disease modelling allows the estimation of longterm prognoses based on available data. In the absence of population trials or observational studies, the model can be thought of as generating hypotheses requiring confirmation rather than providing definitive answers. Within these limitations, tentative conclusions can be drawn. Generally, the addition of screening for microalbuminuria and retinopathy and, if detected, followed by appropriate treatment is likely to be cost saving, with a reduction in the cumulative incidence of end stage renal disease and blindness respectively. In the case of MAU screening and treatment, an improvement in life expectancy is likely. The strategy $\mathrm{C}+\mathrm{EYE}+\mathrm{ACE}$ is most efficient in economic terms but the strategy $\mathrm{I}+\mathrm{EYE}+\mathrm{ACE}$ is the intervention strategy most likely to achieve St. Vincent Declaration targets, with improved life expectancy and decreased long-term diabetes complications, but with increased lifetime costs.

Acknowledgements. This study was partially funded by research grants from Roche Diagnostics Schweiz AG and Roche Diagnostics Boehringer Mannheim GmbH.

\section{References}

1. Schoenle EJ, Molinari L, Bagot M, Semadeni S, Wiesendanger M (1994) Epidemiology of IDDM in Switzerland. Increasing incidence rate and rural-urban differences in Swiss men born 1948-1972. Diabetes Care 17: 955-960
2. Jirovec M, Teuscher A, Bürgi U, Diem P (1993): Diabetesprävalenz in der Schweiz: Berechnung anhand von Medikamentenverkäufen. Schweiz Med Wochenschr 123: 22472250

3. Songer TJ (1992) The economics of diabetes care. In: Alberti KGMM, DeFronzo RA, Keen H, Zimmet P (eds) International textbook of diabetes mellitus John Wiley \& Sons, Chichester, New York, Brisbane, Singapore, Toronto

4. Borch-Johnsen K, Wenzel H, Viberti GC, Mogensen CE (1993) Is screening and intervention for microalbuminuria worthwhile in patients with insulin dependent diabetes? BMJ 306: 1722-1725

5. The DCCT Research Group (1995) Resource utilization and costs of care in the Diabetes Control and Complications Trial. Diabetes Care 18: 1468-1478

6. The DCCT Research Group (1996) Lifetime benefits and costs of intensive therapy as practiced in the Diabetes Control and Complications Trial. JAMA 276: 1409-1416

7. U.S. Department of Health and Human Services. Public Health Service (1996). Cost-effectiveness in health and medicine. Report to the U.S. Public Health Service by the panel on cost-effectiveness in health and medicine. U.S. Government Printing Office

8. Bundesamt für Sozialversicherung [Federal Office of Social Insurance] (1998) Handbuch zur Standardisierung der medizinischen und wirtschaftlichen Bewertung medizinischer Leistungen. [Manual for the standardisation of clinical and economic evaluation of medical technology]. Bern, Swiss Federal Office of Social Security

9. The DCCT Research Group (1993) The effect of intensive treatment of diabetes on the development and progression of long-term complications in insulin-dependent diabetes mellitus. N Engl J Med 329: 977-986

10. The DCCT Research Group (1986) The diabetes control and complications trial (DCCT):design and methodological considerations for the feasibility phase. Diabetes 35 : $530-545$

11. National Cholesterol Education Program (1994) Second Report of the Expert Panel on Detection, Evaluation, and Treatment of High Blood Cholesterol in Adults (Adult Treatment Panel II). Circulation 89: 1333-1445

12. Bennett N, Dodd T, Flatley J, Freeth S, Bolling K (1995) Health survey for England 1993. London, HMSO

13. Arzneimittelkompendium der Schweiz (1996) Basel, Documed AG

14. SVK (Schweizerischer Verband für Gemeinschaftsaufgaben der Krankenversicherer). Geschäftsbericht 1997. Biberist, Büetiger AG

15. Eidgenössisches Departement des Inneren: Analyseliste mit Tarif. (1994) Bern, Eidgenössische Drucksachen- und Materialzentrale

16. $\mathrm{H}+$ Spitalstatistiken, Medizinische Gesamtstatistik der Schweizer Spitäler 1996. (1997) 27th edition. Aarau, H + Verlag

17. Konkordat der Schweizerischen Krankenversicherer: Tagestaxen in Heilanstalten (1996). KSK-Tarifabteilung

18. SVK (Schweizerischer Verband für Gemeinschaftsaufgaben der Krankenversicherer). Geschäftsbericht 1995 Berne, STG-Coopers and Lybrand SA

19. Sagmeister M, Gesner U, Oggier U, Horisberger B (1995) Die Kosten der koronaren Herzerkrankug in der Schweiz 1993 und deren Entwicklung seit 1988. St. Gallen, Forschungsgruppe für Management im Gesundheitswesen an der Hochschule für Wirtschafts- und Sozialwissenschaften St. Gallen

20. Ganiats TG (1997) Prevention, policy, and paradox: what is the value of future health? Am J Prev Med 13: 12-17 
21. Van Hout BA (1998) Discounting costs and effects: a reconsideration. Health Economics 7: 581-594

22. Jensen-Urstad KJ, Reichard PG, Rosfors JS, Lindblad LE, Jensen-Urstad MT (1996) Early atherosclerosis is retarded by improved long-term blood glucose control in patients with IDDM. Diabetes 45: 1253-1258

23. Bundesamt für Statistik: Statistisches Jahrbuch der Schweiz (1997) Neue Zürcher Zeitung

24. The DCCT Research Group (1996) The absence of a glycemic threshold for the development of long-term complications. The perspective of the DCCT. Diabetes 45: 12891298

25. Viberti G, Mogensen CE, Groop LC, Pauls JF (1994) Effect of captopril on progression to clinical proteinuria in patients with insulin-dependent diabetes mellitus and microalbuminuria. JAMA 271: 275-279

26. Laffel LM, McGill JB, Gans DJ (1995) The beneficial effect of angiotensin-converting enzyme inhibition with captopril on diabetic nephropathy in normotensive IDDM patients with microalbuminuria. North American Microalbuminuria Study Group. Am J Med 99: 497-504

27. The Microalbuminuria Captopril Study Group (1996) Captopril reduces the risk of nephropathy in IDDM patients with microalbuminuria. Diabetologia 39: 587-593

28. Krolewski AS, Warram JH, Christlieb AR, Busick EJ, Kahn CR (1985) The changing natural history of nephropathy in type I diabetes. Am J Med 78: 785-794

29. Lewis EJ, Hunsicke LG, Bain RP, Rohde RD (1993) The effect of angiotensin-converting-enzyme inhibition on diabetic nephropathy. The Collaborative Study Group. N Engl J Med 329: 1456-1462

30. Ismail N, Hakim RM, Oreopoulos DG, Patrikarea A (1993) Renal replacement therapies in the elderly: Part 1. Hemodialysis and chronic peritoneal dialysis. Am J Kidney Dis 22: 759-782

31. Najarian J, Kaufman DB (1989) Long-term survival following kidney transplantation in 100 type I diabetic patients. Transplantation 47: 106-113

32. D'Amico DJ (1994) Diseases of the retina. N Engl J Med 331: 95-106

33. American Diabetes Association (1996) Diabetes. Vital Statistics

34. Klein R, Klein BEK, Moss SE, Davis MD, DeMets DL (1999) Glycosylated hemoglobin predicts the incidence and progression of diabetic retinopathy. JAMA 260: 2864-2871

35. Klein R, Klein BEK, Moss SE (1989) The Wisconsin Epidemiology study of Diabetic Retinopathy. IX. Four year incidence and progression of diabetic retinopathy when age at diagnosis is less than 30 years. Arch Ophthalmol 107: 237-243

36. The Diabetic Retinopathy Study Group (1981) Photocoagulation treatment of proliferative diabetic retinopathy. Clinical application of Diabetic Retinopathy Study (DRS) findings, DRS report number 8. Ophthalmology 88: 583-600

37. Kannel WB, D'Agostino RB, Wilson PW, Belanger AJ, Gagnon DR (1990) Diabetes, fibrinogen, and risk of cardiovascular disease: the Framingham experience. Am Heart J 120: 672-676

38. Anderson KM, Odell PM, Wilson PW, Kannel WB (1991) Cardiovascular disease risk profiles. Am Heart J 121: 293-298

39. Karlson B, Herlitz J, Hjalmarson A (1993) Prognosis of acute myocardial infarction in diabetic and non-diabetic patients. Diab Med 10: 449-454

40. Donahue RP, Goldberg RJ, Chen Z, Gore JM, Alpert JS (1993) The influence of sex and diabetes mellitus on surviv- al following acute myocardial infarction: a communitywide perspective. J Clin Epidemiol 46: 245-252

41. Herlitz J, Bang A, Karlson BW (1996) Mortality, place and mode of death and reinfarction during a period of 5 years after acute myocardial infarction in diabetic and non-diabetic patients. Cardiology 87: 423-428

42. Zuanetti G, Latini R, Maggioni AP, Santoro L, Franzosi MG (1993) Influence of diabetes on mortality in acute myocardial infarction: data from the GISSI-2 study. J Am Coll Cardiol 22: 1788-1794

43. Wolf PA, D'Agostino RB, Belanger AJ, Kannel WB (1991) Probability of stroke: a risk profile from the Framingham study. Stroke 22: 312-318

44. Sprafka JM, Virnig BA, Shahar E, McGovern PG (1994) Trends in diabetes prevalence among stroke patients and the effect of diabetes on stroke survival: the Minnesota Heart Survey. Diabet.Med 11: 678-684

45. Sacco RL, Wolf PA, Kannel WB, McNamara PM (1982) Survival and recurrence following stroke. The Framingham study. Stroke 13: 290-295

46. Most RS, Sinnock P (1983) The epidemiology of lower extremity amputations in diabetic individuals. Diabetes Care 6: 87-91

47. McNeely MJ, Boyko EJ, Ahroni JH, Stensel VL, Reiber GE, Smith DG, Pecoraro RF (1995) The independent contributions of diabetic neuropathy and vasculopathy in foot ulceration. How great are the risks? Diabetes Care 18: 216-219

48. Moss SE, Klein R, Klein BE(1992) The prevalence and incidence of lower extremity amputation in a diabetic population. Arch Intern Med 152: 610-616

49. Bild DE, Selby JV, Sinnock P, Browner WS, Braveman P, Showstack JA (1989) Lower-extremity amputation in people with diabetes. Epidemiology and prevention. Diabetes Care 12: 24-31

50. Fylling CP, Knighton Dr (1989) Amputation in the diabetic population: incidence, causes cost, treatment, and prevention. J Enterostomal Ther 16: 247-255

51. Herings RM, de Boer A, Stricker BH, Leufkens HG, Porsius A (1995) Hypoglycaemia associated with use of inhibitors of angiotensin converting enzyme. Lancet 345: 1195-1198

52. Umpierrez GE, Khajavi M, Kitabchi AE (1996) Review: diabetic ketoacidosis and hyperglycemic hyperosmolar nonketotic syndrome. Am J Med Sci 311: 225-233

53. Javitt JC, Aiello LP, Chiang Y, Ferris FL, Canner JK, Greenfield S (1994) Preventive eye care in people with diabetes is cost-saving to the federal government. Implications for health-care reform. Diabetes Care 17: 909-917

54. Diabetes care and research in Europe (1990) The Saint Vincent Declaration. IDF Bulletin 35: 7-8

55. Mason J, Drummond M, Torrance G (1993) Some guidelines on the use of cost effectiveness league tables. BMJ 306: 570-572

56. Laupacis A, Feeny D, Detsky AS, Tugwell PX (1992) How attractive does a new technology have to be to warrant adoption and utilization? Tentative guidelines for using clinical and economic evaluations. CMAJ 146: 473-481

57. Arbeitsgruppe der Schweizerischen Diabetes-Stiftung (1996) Die St. Vincent-Deklaration:eine Umfrage zur Diabetiker-Betreuung in der Schweiz. Schweizerische Ärztezeitung 77: 668-675

58. Schnieder H, Jutzi E, Lischinski M (1992) Wie lange leben Diabetiker? Erhebung zur Überlebenszeit von Diabetikern in einer "geschlossenen" Population. Diabetes-Journal Schulungs-Profi 4: 4-11

59. Javitt JC, Aiello LP, Bassi LJ, Chiang YP, Canner JK (1991) Detecting and treating retinopathy in patients with type I 
diabetes mellitus. Savings associated with improved implementation of current guidelines. American Academy of Ophthalmology. Ophthalmology 98: 1565-1573

60. Byford S, Palmer S (1998) Common errors and controversies in pharmacoeconomic analyses. Pharmacoeconomics 13: 659-666

61. Jensen-Urstad KJ, Reichard PG, Rosfors JS, Lindblad LE, Jensen-Urstad MT (1996) Early atherosclerosis is retarded by improved long-term blood glucose control in patients with IDDM. Diabetes 45: 1253-1258

62. Pharoah P, Hollingworth W (1996) Cost effectiveness of lowering cholesterol concentration with statins in patients with and without pre-existing coronary heart disease: a life table method applied to health authority population. BMJ 312: $1443-1448$

63. The DCCT Research Group (1995) Implementation of treatment protocols in the Diabetes Control and Complications Trial. Diabetes Care 18: 361-376

64. Jackson WE, Holmes DL, Garg SK, Harris S, Chase HP (1992) Angiotensin-converting enzyme inhibitor therapy and diabetic retinopathy. Ann Ophthalmol 24: 99-103

65. Chase HP, Garg SK, Harris S, Jackson WE, Holmes DL (1993) Angiotensin-converting enzyme inhibitor treatment for young normotensive diabetic subjects: a two-year trial. Ann Ophthalmol 25: 284-289

66. Chaturvedi N, Sjolie AK, Stephenson JM et al. (1998) Effect of lisinopril on progression of retinopathy in normotensive people with type 1 diabetes. The EUCLID Study Group. EURODIAB Controlled Trial of Lisinopril in Insulin-Dependent Diabetes Mellitus. Lancet 351: 28-31

67. Reja A, Tesfaye S, Harris ND, Ward JD (1995) Is ACE inhibition with lisinopril helpful in diabetic neuropathy? Diabet Med 12: 307-309

68. Al-Memar AY, Wimalaratana HSK, Millward BA (1996) Improvement of neurological measures of nerve function with the ACE inhibitor, lisinopril in insulin dependent diabetics with peripheral neuropathy? J Neurol Neurosurg Psychiatry 61: 223

69. GISSI-3 (1994) Effects of lisinopril and transdermal glyceryl trinitrate singly and together on 6-week mortality and ventricular function after acute myocardial infarction. Gruppo Italiano per lo Studio della Sopravvivenza nell'infarto Miocardico. Lancet 343: 1115-1122

70. Ambrosioni E, Borghi C, Magnani B (1995) The effect of the angiotensin-converting-enzyme inhibitor zofenopril on mortality and morbidity after anterior myocardial infarction. The Survival of Myocardial Infarction Long-Term Evaluation (SMILE) Study Investigators. N Engl J Med 332: 80-85

71. Pfeffer MA, Braunwald E, Moye LA et al. (1992) Effect of captopril on mortality and morbidity in patients with left ventricular dysfunction after myocardial infarction. Results of the survival and ventricular enlargement trial. The SAVE Investigators. N Engl J Med 327: 669-677

72. Kober L, Torp-Pedersen C, Carlsen JE (1995) A clinical trial of the angiotensin-converting-enzyme inhibitor trandolapril in patients with left ventricular dysfunction after myocardial infarction. Trandolapril Cardiac Evaluation (TRACE) Study Group. N Engl J Med 333: 16701676

73. Malmberg K (1997) Prospective randomised study of intensive insulin treatment on long term survival after acute myocardial infarction in patients with diabetes mellitus. DIGAMI (Diabetes Mellitus, Insulin Glucose Infusion in Acute Myocardial Infarction) Study Group. BMJ 314: $1512-1515$

74. U.K. Prospective Diabetes Study Group (1998) Efficacy of atenolol and captopril in reducing risk of macrovascular and microvascular complications in type 2 diabetes: UKPDS 39. BMJ 317: 713-720

75. Colwell JA (1997) Aspirin therapy in diabetes. Diabetes Care 20: 1767-1771

76. The DCCT Research Group (1996) Influence of intensive diabetes treatment on quality-of-life outcomes in the diabetes control and complications trial. Diabetes Care 19: 195-203

77. Schweizerische Unfallversicherungsanstalt (SUVA) (1997) Spitalleistungskatalog. Luzern.

78. Javor K A (1997) Diabetic ketoacidosis charges relative to medical charges of adult patients with type I diabetes. Diabetes Care 20: 349-354 